\title{
Aluminosilicate mineralogy and the sorption of organic cations: Interactions between electrostatic barriers and compound structural features
}

William C. Jolint, Alissa Richard§, Dharni Vasudevanж , Jose A. Gascon§ and Allison A. MacKay $\ddagger^{*}$

† Department of Civil and Environmental Engineering, University of Connecticut, Storrs, CT 06269

$\S$ Department of Chemistry, University of Connecticut, Storrs, CT 06269

ж Department of Chemistry, Bowdoin College, Brunswick, ME 04011

‡ Department of Civil, Environmental and Geodetic Engineering, The Ohio State University, Columbus, $\mathrm{OH} 43210$

*Corresponding Author Email: mackay.49@osu.edu

\section{Contents}

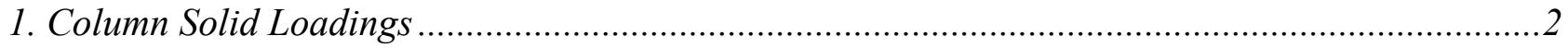

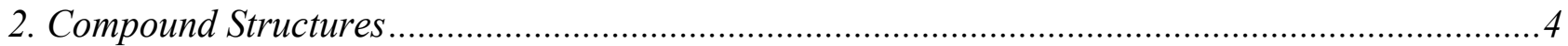


3. Aluminosilicate minerology used in molecular dynamics .................................................6

4. Calculations of the interlayer electrostatic potential................................................................ 7

5. $1 D$ representations of the interlayer electrostatic potential. ..................................................... 7

6. Electrostatic potential maps for benzylamine and naphthylmethylamine ..................................8

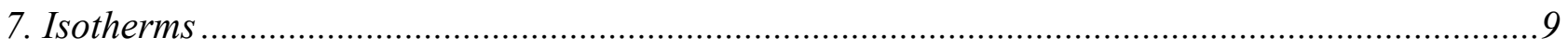

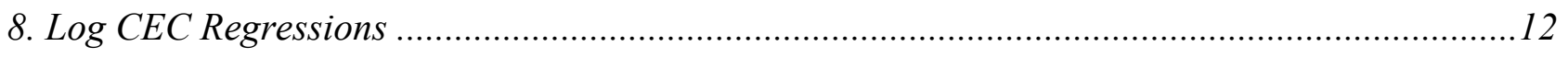

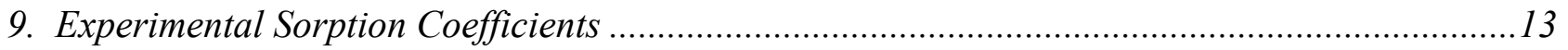

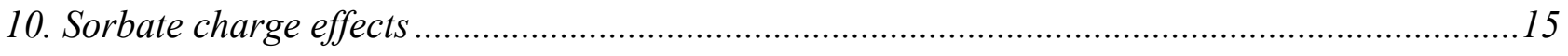

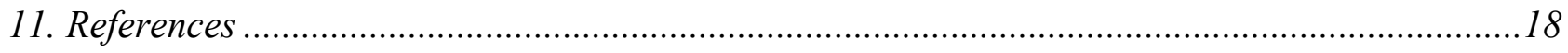

\section{Column Solid Loadings}

Columns (30-mm length, 2.1-mm inner diameter, Restek \#25118) were manually packed with a mixture of silicon carbide $(\mathrm{SiC})$ and test aluminosilicate material for the 'aluminosilicate-SiC' columns and with $\mathrm{SiC}$ for the 'SiC-only' columns. SiC-to-sorbent ratios (Table $\mathrm{S} 1$ ) were chosen so that the center of mass of the breakthrough curves for the test compounds was at least 1.5 times greater than for a non-retained tracer $\left(\mathrm{NO}^{3-}\right)$ while minimizing peak spreading associated with extended compound retention times. An additional column with decreased solid loadings (denoted by parenthesis, Table S1) were required for hectorite, Tx-montmorillonite, and nontronite since sorption coefficients of pharmaceuticals were much higher and resulted in non-detectable peaks. 
Table S1. Experimental conditions used in the test columns. Values in parentheses indicate columns at lower solid loadings.

\begin{tabular}{|l|l|l|l|l|l|l|l|l|}
\hline Sorbent & Hectorite & $\begin{array}{l}\text { Tx- } \\
\text { montmorillonite }\end{array}$ & $\begin{array}{l}\text { Wy- } \\
\text { montmorillonite }\end{array}$ & Vermiculite & Nontronite & Chlorite & Illite & Kaolinite \\
\hline $\begin{array}{l}\text { Void Space } \\
(\mu \mathrm{L})\end{array}$ & $45(45)$ & $48(45)$ & 48 & 45 & $47(48)$ & 46 & 48 & 37 \\
\hline $\begin{array}{l}\text { Sorbent } \\
\text { Mass (mg) }\end{array}$ & $1.5(0.25)$ & $0.71(0.25)$ & 0.80 & 0.5 & $0.9(0.2)$ & 8.2 & 2.9 & 27 \\
\hline $\begin{array}{l}\text { Sorbent-to- } \\
\text { water ratio } \\
(\mathrm{g} / \mathrm{L})\end{array}$ & $35(5.8)$ & $15(5.8)$ & 18 & 13 & $19(4.0)$ & 177 & 61 & 712 \\
\hline
\end{tabular}




\section{Compound Structures}

(1)

Figure S1. Compounds structures of benzylamine-based compounds: (1) benzylamine: (BA) , (2) N-benzylmethylamine: N-BMA, (3) N,N-dimethylbenzylamine: N,N-DMBA benzyltrimethylammonium: BTMA (5) phenyltrimethylammonium: PTMA, (6) 2,4dimethylbenzylamine: 2,4,-di- $\mathrm{CH}_{3}$-BA, (7) 2,4-dichlorobenzylamine: 2,4,-di-Cl-BA, naphthylmethylamine: NMA, (9) 4-aminobenzylamine: 4- $\mathrm{NH}_{2} \mathrm{BA}$, (10) 4-nitrobenzylamine: 4- $\mathrm{NO}_{2}$ BA, (11) 4-trifluoromethylbenzylamine: 4- $\mathrm{CF}_{3} \mathrm{BA}$, (12) 4-methoxybenzylamine: 4- $\mathrm{OCH}_{3} \mathrm{BA}$, (13) 4-aminomethylbenzoic acid, (14) aniline. 


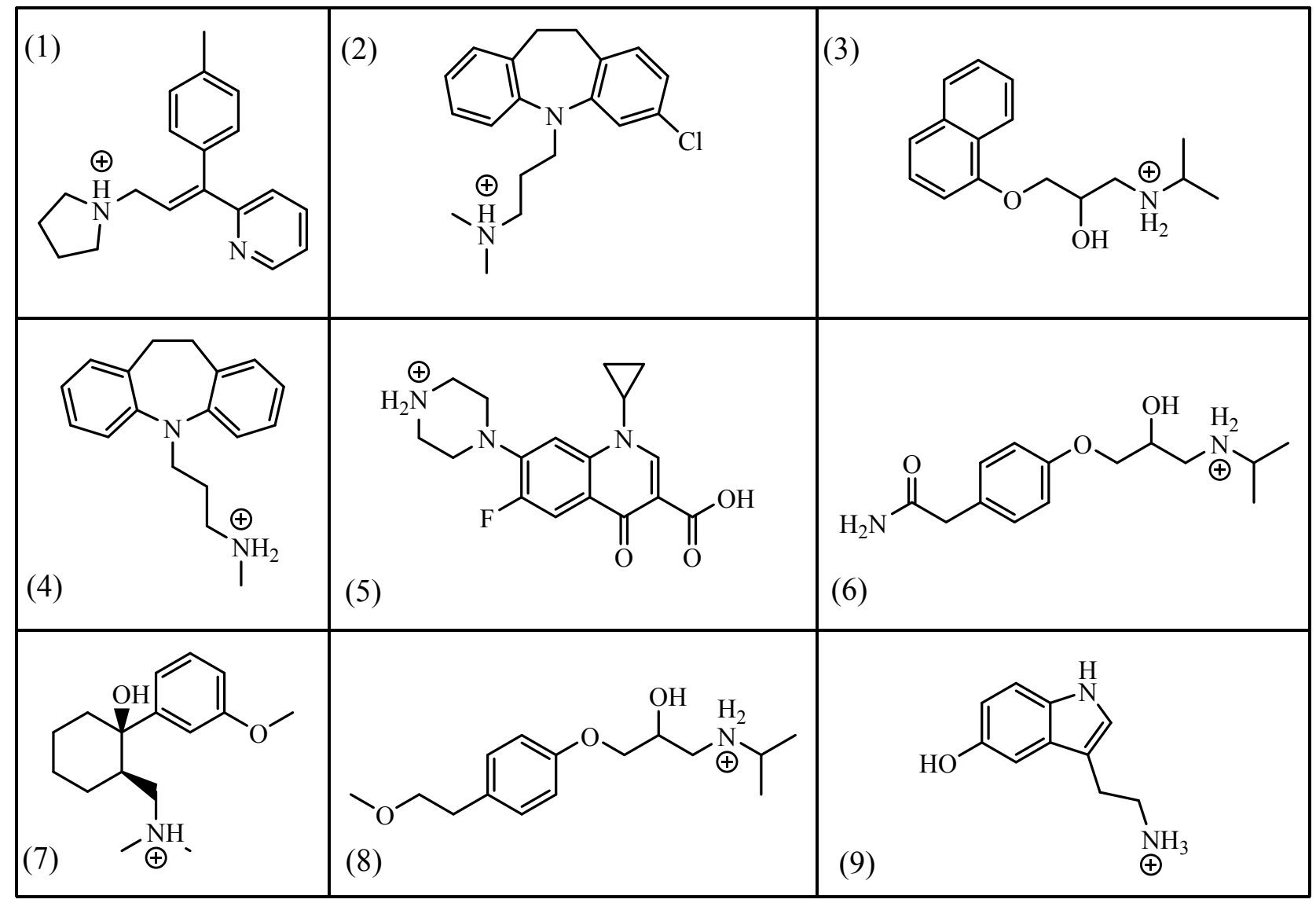

Figure S2. Pharmaceutical compounds structures: (1) triprolidine, (2) clomipramine, (3) propranolol, (4) desipramine, (5) ciprofloxacin, (6) atenolol, (7) tramadol, (8) metoprolol, (9) serotonin. 


\section{Aluminosilicate minerology used in molecular dynamics}

Table S2: Characteristic mineralogy of four smectites. In this study, nontronite, montmorillonite (MNT), vermiculite, and hectorite were used to evaluate electrostatic differences and the effect of aluminosilicate mineralogy on the organic cation sorption

\begin{tabular}{|l|l|l|l|}
\hline Clay & $\mathbf{1 / 2}$ Unit Cell Formula & $\begin{array}{l}\text { Octahedral } \\
\text { Occupation }\end{array}$ & Substitution Ratio \\
\hline Hectorite & $\mathrm{Na}_{0.4}\left(\mathrm{Mg}_{2.6}, \mathrm{Li}_{0.4}\right) \mathrm{Si}_{4} \mathrm{O}_{10}(\mathrm{~F}, \mathrm{OH})_{2}$ & Trioctahedral & $1: 9$ Octahedral \\
\hline Montmorillonite & $\mathrm{Na}_{0.4}\left(\mathrm{Al}_{1.6}, \mathrm{Mg}_{0.4}\right)\left(\mathrm{Si}_{3.9}, \mathrm{Al}_{0.1}\right)$ & Dioctahedral & $1: 8$ Octahedral \\
& $\mathrm{O}_{10}(\mathrm{OH})_{2}$ & & $1: 32$ Tetrahedral \\
\hline Vermiculite & $\mathrm{Na}_{0.7}\left(\mathrm{Al}_{1.4}, \mathrm{Mg}_{0.3}, \mathrm{Fe}_{0.3}\right)\left(\mathrm{Si}_{3.6}, \mathrm{Al}_{0.4}\right)$ & Dioctahedral & $1: 8$ Octahedral \\
& $\mathrm{O}_{10}(\mathrm{OH})_{2}$ & $1: 8$ Tetrahedral \\
\hline Nontronite & $\mathrm{Na}_{0.4} \mathrm{Fe}_{2}\left(\mathrm{Si}_{3.6}, \mathrm{Al}_{0.4}\right) \mathrm{O}_{10}(\mathrm{OH})_{2}$ & Dioctahedral & $1: 12$ Tetrahedral \\
\hline
\end{tabular}




\section{Calculations of the interlayer electrostatic potential.}

The calculation of $\phi$ at the interlayer was carried out with the program Tinker. ${ }^{1}$ For each of the four aluminosilicates, a positive unit charge $(+1 e)$ was inserted into the interlayer of the substituted aluminosilicate conformation to serve as a probe for the calculation of electrostatic potentials at locations throughout the interlayer space. A three-dimensional grid was generated in the interlayer region of the aluminosilicate model for each random substitution of a given aluminosilicate. The position of the unit charge was varied systematically within the grid and the electrostatic potential $(\phi)$ was calculated for each grid location. Finally, the value of $\phi$ at each grid point was averaged over the 10 conformations for a given aluminosilicate. The products of these simulations were threedimensional point maps of electrostatic potential within the interlayer space for each of the modeled aluminosilicates.

\section{5. $1 D$ representations of the interlayer electrostatic potential.}

Figure 3 of the main manuscript gives a 3-dimensional visual representation of the electrostatic potential in the interlayer averaged over multiple charge substitution configurations. It is also convenient to visualize, for a single charge substitution, a typical shape of the electrostatic potential along a particular dimension. Figure $\mathrm{S} 3$ shows the fluctuations of $\phi$ along the $\mathrm{x}$ and $\mathrm{z}$ directions within the interlayer. In both cases, the barriers are larger for nontronite than for hectorite. This is consistent with the idea that, as the cation charge becomes more defocused (as we have shown previously ${ }^{2}$ ), going from a primary to a quaternary amine, a positive charge feels a higher potential energy. That is what we mean by lower or higher penalty. That is, in octahedral substituted aluminosilicates, it is easier (lower penalty) to defocus the charge on a larger region than it is for the tetrahedral cases. 

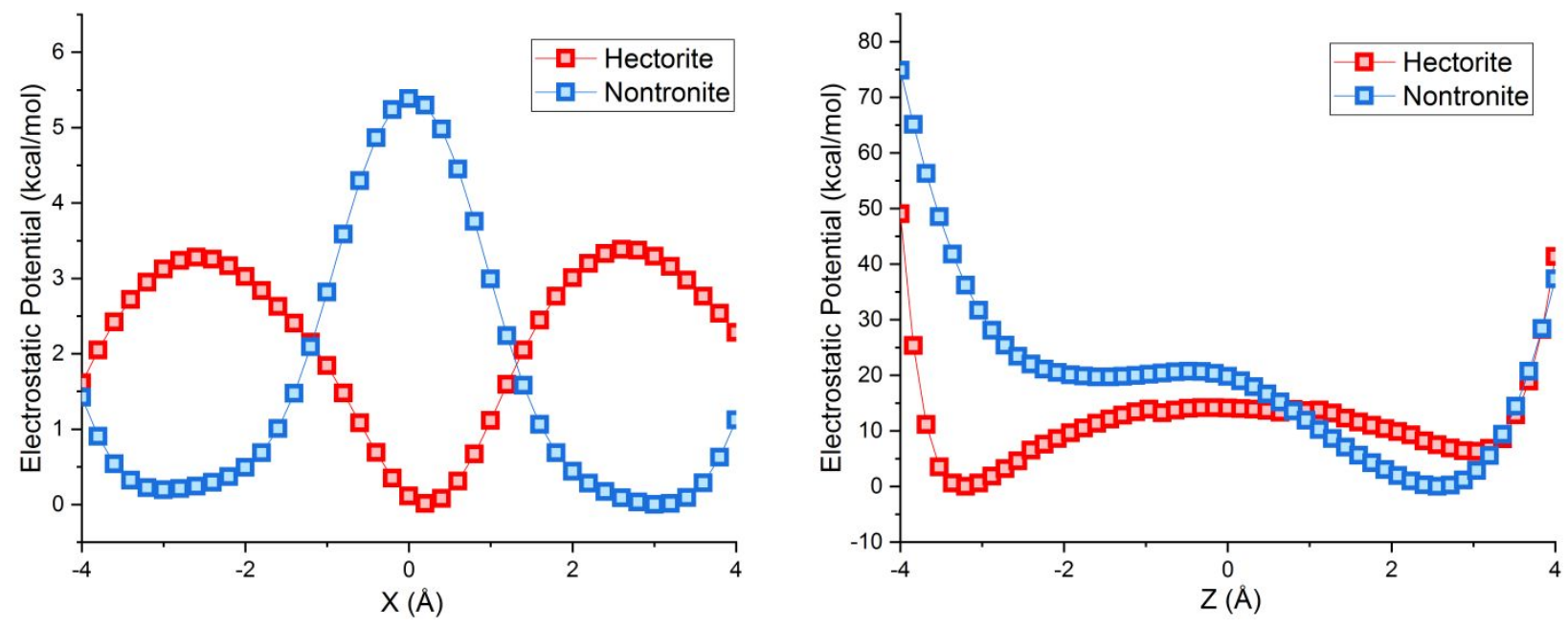

Figure S3. One-dimensional visual representation on the $\mathrm{X}$ (left) and $\mathrm{Z}$ axes (right) of the electrostatic potential fluctuations within the interlayers of smectite aluminosilicates with octahedral (hectorite) and tetrahedral (nontronite) charge sites. Potentials were shifted so that the minimum value correspond to $\phi=0$. In both figures, the origin was placed at the geometric center of the interlayer. These calculations were obtained for a single arbitrary charge substitution. 


\section{Electrostatic potential maps for benzylamine and naphthylmethylamine}

All the molecular electrostatic potential (MEP) maps shown in the main manuscript and in Figure S4 were created with Gaussview with an isodensity of 0.005 . The electron density and the MEP used by Gaussview were obtained with the quantum chemistry software Gaussian at the B3LYP/6$31 \mathrm{~g}(\mathrm{~d})$ level of theory.
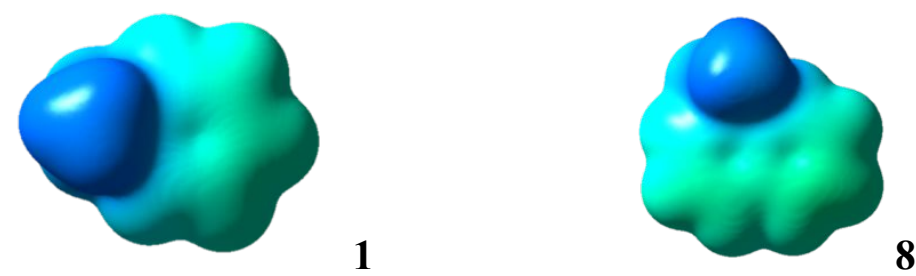

$0.275 e 0$ $-0.275 \mathrm{e} 0\left(\mathrm{e} / \mathrm{bohr}^{3}\right)$

Figure S4. Electrostatic potential maps for benzylamine (1) and naphthylmethylamine (8). Note that scale is slightly different than that of Figure $2 \mathrm{C}$ and Figure $4 \mathrm{~A}$ 


\section{Isotherms}

For benzylamine, sorption isotherms were obtained for each of the 8 test aluminosilicates. Sorption coefficients obtained were converted to the corresponding aqueous $\left(C_{w}, \mathrm{mM}\right)$ and sorbed $\left(C_{s}, \mathrm{mmol} \mathrm{\textrm {kg } ^ { - 1 } ) \text { concentrations }}{ }^{3}\right.$ :

$$
\begin{gathered}
C_{w}=\frac{C_{0} * V_{i}}{K_{d} * m+V_{i}} \\
C_{s}=\frac{C_{0} * V_{i}-C_{w} * V_{i}}{m}
\end{gathered}
$$

where $C_{0}(\mathrm{mM})$ is the concentration of the injected test compound solution and $V_{i}(\mathrm{~L})$ is the injected solution volume. Paired $C_{w}$ and $C_{s}$ values were used to construct isotherms. For the purposes of evaluating isotherm linearity, the Langmuir-Freundlich isotherm equation was used: ${ }^{27}$

$$
C_{s}=\frac{C_{s, \max }\left(K_{L F} C_{w}\right)^{h}}{1+\left(K_{L F} C_{w}\right)^{h}}
$$

where $C_{s, \max }$ is assumed to be the CEC of the aluminosilicate, $K_{L F}$ is the sorbate affinity, and $h$ reflects isotherm non-linearity ( $h>1$ for convex isotherms and $h<1$ for concave isotherms). The Langmuir-Freundlich equation was log-transformed for fitting4:

$$
\log \left(\frac{C_{S}}{C_{S, \max }-C_{S}}\right)=h \log \left(C_{w}\right)+h \log \left(K_{L F}\right)
$$

To evaluate how aluminosilicate mineralogy influences isotherm linearity, we further investigated isotherms for benzylamine sorption onto our eight test aluminosilicates. The range of benzylamine masses injected to the columns was sufficiently wide that sorbed phase concentrations approached the cation exchange capacity of the aluminosilicates at the highest aqueous 
concentrations. Our complete isotherms revealed two distinct isotherm patterns for benzylamine sorption (Figure S5). Aluminosilicates without an interlayer (chlorite, illite and kaolinite) displayed the traditional concave shape (relative to the $x$-axis) indicative of surface site saturation with increasing aqueous concentration. In contrast, aluminosilicates with an interlayer (hectorite, montmorillonite, vermiculite, and nontronite) showed S-shaped isotherms that were convex in shape at low concentrations with a change in curvature to concave in shape for sorbed concentrations that approached the aluminosilicate cation exchange capacity. Such an S-isotherm shape has been previously attributed to sorbate-to-sorbate pi-cation interactions. ${ }^{4}$ These differences in isotherm shape with interlayer absence/presence were also confirmed by the " $h$ " values obtained from fits of the Langmuir-Freundlich equation (Eq. S4). For each aluminosilicate grouping, $h$-values fell within a narrow range. Aluminosilicates without an interlayer had $h$-values less than $1(0.80 \pm 0.07)$ as to be expected for concave isotherms; whereas, aluminosilicates with an interlayer had $h$ values greater than $1(1.56 \pm 0.05)$ (Table S3). Together, isotherm shape and Langmuir-Freundlich $h$-values indicated that sorbate-to-sorbate interactions are only important for aluminosilicates with interlayers. We note that subsequent experiments with other test amine compounds used experimental conditions that were selected to obtain linear range $K_{d}$ values ${ }^{5}$ and ensure that sorbate-to-sorbate interactions did not occur. 

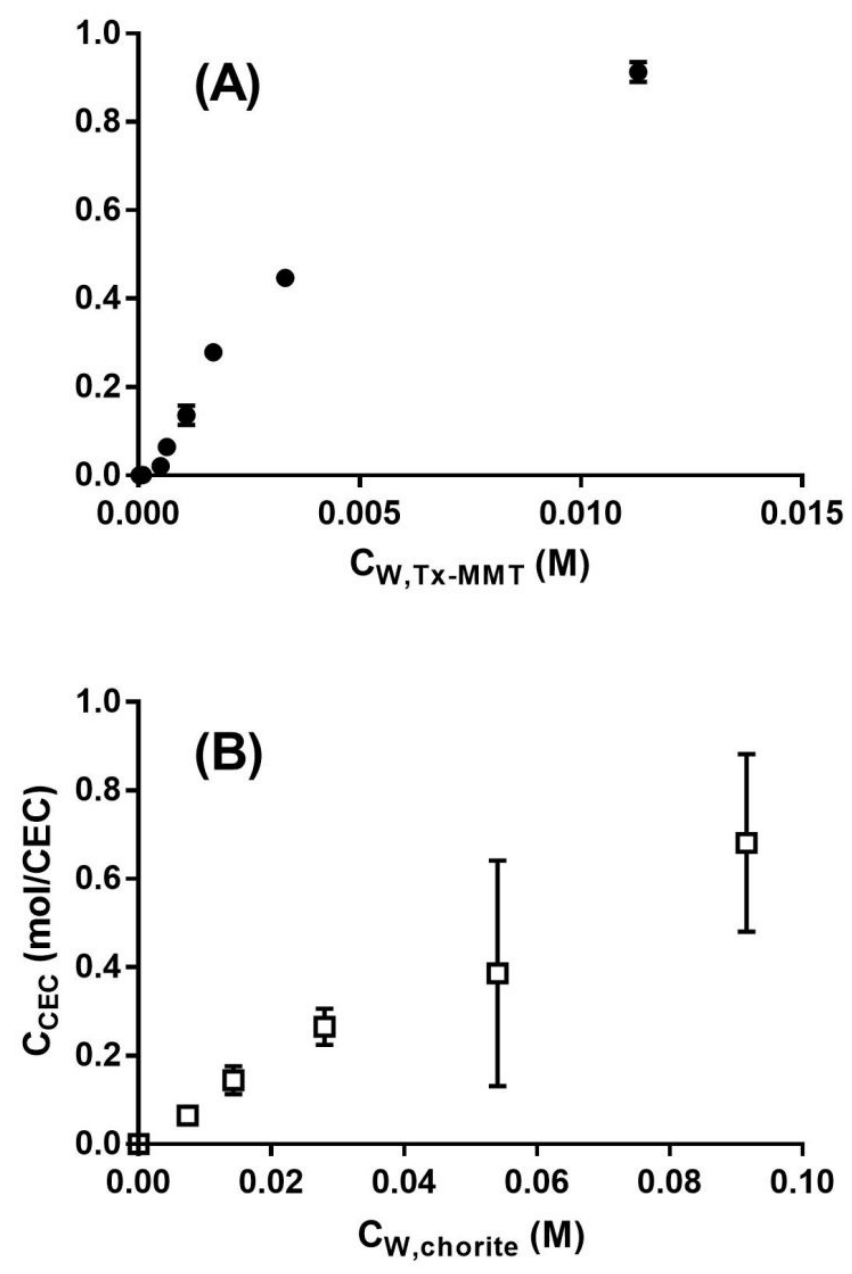

Figure S5. Sorption isotherms for benzylamine to (A) an aluminosilicate with an interlayer, Txmontmorillonite (black circles) and (B) an aluminosilicate without an interlayer, chlorite (white squares) have markedly different shapes. 
Table S3. " $\mathrm{h}$ " values and $\mathrm{K}_{\mathrm{lf}}$ values for the benzylamine sorption to the 8 aluminosilicates

\begin{tabular}{|l|r|r|}
\hline Clay & "h" & $\mathbf{l o g} \mathbf{K}_{\mathbf{l f}}$ \\
\hline Hectorite & 1.61 & 2.73 \\
\hline Tx-MMT & 1.6 & 2.37 \\
\hline Wy-MMT & 1.56 & 2.42 \\
\hline Vermiculite & 1.49 & 2.33 \\
\hline Nontronite & 1.54 & 2.60 \\
\hline Chlorite & 0.88 & 0.72 \\
\hline Illite & 0.78 & 1.53 \\
\hline Kaolinite & 0.74 & 0.05 \\
\hline
\end{tabular}




\section{Log CEC Regressions}

Table S4: Correlation between $\log K_{d}$ and $\log$ CEC for all test compounds and aluminosilicates investigated (listed in the order of strongest to weakest correlation; $1^{\circ}, 2^{\circ}, 3^{\circ}, 4^{\circ}$ refer to primary, secondary, tertiary, and quaternary amines, respectively)

\begin{tabular}{|c|c|c|c|}
\hline Compound & Slope & $\mathbf{R}^{\wedge} 2$ & p-value \\
\hline \multicolumn{4}{|c|}{ Benzylamine derivatives, Aniline and PTMA } \\
\hline Naphthylmethylamine $\left(1^{\circ}\right)$ & 1.36 & 0.99 & $<0.05$ \\
\hline Benzylamine $\left(1^{\circ}\right)$ & 1.18 & 0.99 & $<0.05$ \\
\hline 4-methoxybenzylamine $\left(1^{\circ}\right)$ & 1.11 & 0.96 & $<0.05$ \\
\hline 2,4-Dichlorobenzylamine $\left(1^{\circ}\right)$ & 1.18 & 0.95 & $<0.05$ \\
\hline 4-nitrobenzylamine $\left(1^{\circ}\right)$ & 0.94 & 0.94 & $<0.05$ \\
\hline 2,4-Dimethylbenzylamine $\left(1^{\circ}\right)$ & 1.39 & 0.94 & $<0.05$ \\
\hline 4-aminobenzylamine $\left(1^{\circ}\right)$ & 1.09 & 0.93 & $<0.05$ \\
\hline n-benzylmethylamine $\left(2^{\circ}\right)$ & 1.26 & 0.91 & $<0.05$ \\
\hline 4-(trifluoromethyl)benzylamine $\left(1^{\circ}\right)$ & 1.06 & 0.88 & $<0.05$ \\
\hline n,n-dimethylbenzylamine $\left(3^{\circ}\right)$ & 1.38 & 0.84 & $<0.05$ \\
\hline Phenyltrimethylammonium $\left(4^{\circ}\right)$ & 1.24 & 0.81 & $<0.05$ \\
\hline Benzyltrimethylammonium $\left(4^{\circ}\right)$ & 1.11 & 0.77 & $<0.05$ \\
\hline Aniline $\left(1^{\circ}\right)$ & 1.28 & 0.75 & 0.01 \\
\hline 4-Aminomethylbenzoic acid $\left(1^{\mathrm{o}}\right)^{\mathrm{b}}$ & 0.45 & 0.33 & 0.14 \\
\hline \multicolumn{4}{|c|}{ Pharmaceuticals ${ }^{\mathrm{c}}$} \\
\hline Clomipramine $\left(3^{\circ}\right)$ & 1.33 & 0.88 & 0.02 \\
\hline Tramadol $\left(3^{\circ}\right)$ & 1.64 & 0.85 & 0.02 \\
\hline Ciprofloxacin $\left(2^{\circ}\right)$ & 1.45 & 0.85 & 0.03 \\
\hline Desipramine $\left(2^{\circ}\right)$ & 2.09 & 0.84 & 0.03 \\
\hline Triprolidine $\left(3^{\circ}\right)^{b}$ & 1.38 & 0.69 & 0.08 \\
\hline Propranolol $\left(2^{\circ}\right)^{b}$ & 1.63 & 0.66 & 0.09 \\
\hline Atenolol $\left(2^{\circ}\right)^{b}$ & 1.16 & 0.61 & 0.12 \\
\hline Metoprolol $\left(2^{\circ}\right)^{b}$ & 1.21 & 0.56 & 0.14 \\
\hline
\end{tabular}

${ }^{a} \mathrm{n}=8$, sorption to 8 aluminosilicates; ${ }^{\mathrm{b}} \mathrm{p}>0.05$, correlation not statistically significant; ${ }^{\mathrm{c}} \mathrm{n}=5$, sorption to 5 aluminosilicates 


\section{Experimental Sorption Coefficients}

Table S5. McGowan molar volumes ( $\mathrm{Vx})$ and sorption coefficients $(\mathrm{L} / \mathrm{kg})$ of benzylamine based compounds for eight aluminosilicates

\begin{tabular}{|c|c|c|c|c|c|c|c|c|c|}
\hline Compound & $\begin{array}{l}x \\
\left(\mathrm{~cm}^{3} / \mathrm{mol}\right)\end{array}$ & $\begin{array}{l}K_{d}(\mathrm{~L} / \mathrm{kg}) \\
\text { Hectorite }\end{array}$ & $\begin{array}{l}K_{d}(\mathrm{~L} / \mathrm{kg}) \mathrm{Tx}- \\
\text { montmorillonite }\end{array}$ & $\begin{array}{l}K_{d}(\mathrm{~L} / \mathrm{kg}) \mathrm{Wy}- \\
\text { montmorillonite }\end{array}$ & $\begin{array}{l}K_{d} \quad(\mathrm{~L} / \mathrm{kg}) \\
\text { Vermiculite }\end{array}$ & $\begin{array}{lr}K_{d}(\mathrm{~L} / \mathrm{kg}) \\
\text { Nontronite }\end{array}$ & $\begin{array}{l}K_{d} \\
(\mathrm{~L} / \mathrm{kg}) \\
\text { Chlorite }\end{array}$ & $\begin{array}{l}K_{d}(\mathrm{~L} / \mathrm{kg}) \\
\text { Illite }\end{array}$ & $\begin{array}{l}K_{d} \quad(\mathrm{~L} / \mathrm{kg}) \\
\text { Kaolinite }\end{array}$ \\
\hline Benzylamine & 0.98 & $10 \pm 1$ & $15 \pm 2$ & $16 \pm 2$ & $15 \pm 1$ & $25 \pm 2.5$ & $0.77 \pm 0.1$ & $4.2 \pm 0.6$ & $0.25 \pm 0.07$ \\
\hline 2,4-Dichlorobenzylamine & 1.25 & $34 \pm 2$ & $31 \pm 3$ & $28 \pm 4$ & $18 \pm 1$ & $27 \pm 3$ & $1 \pm 0.2$ & $10 \pm 1$ & $0.44 \pm 0.07$ \\
\hline 2,4-Dimethylbenzylamine & 1.26 & $28 \pm 4$ & $30 \pm 2$ & $28 \pm 4$ & $14 \pm 1$ & $11 \pm 1$ & $0.45 \pm 0.1$ & $5 \pm 1$ & $0.16 \pm 0.06$ \\
\hline Naphthylmethylamine & 1.35 & $19 \pm 5$ & $63 \pm 3$ & $66 \pm 2$ & $40 \pm 1$ & $45 \pm 3$ & $1.06 \pm 0.2$ & $6 \pm 1$ & $0.34 \pm 0.06$ \\
\hline n-benzylmethylamine & 1.12 & $41 \pm 6$ & $23 \pm 4$ & $24 \pm 2$ & $12 \pm 2$ & $23 \pm 6$ & $1.25 \pm 0.3$ & $3 \pm 0.5$ & $0.2 \pm 0.04$ \\
\hline n,n-dimethylbenzylamine & 1.26 & $382 \pm 2$ & $108 \pm 9$ & $83 \pm 9$ & $60 \pm 5$ & $78 \pm 6$ & $4.06 \pm 0.4$ & $9 \pm 0.5$ & $0.6 \pm 0.1$ \\
\hline Benzyltrimethylammonium & 1.4 & $733 \pm 57$ & $191 \pm 10$ & $175 \pm 9$ & $100 \pm 15$ & $110 \pm 2$ & $12 \pm 1.5$ & $20 \pm 2$ & $3.01 \pm 0.37$ \\
\hline Phenyltrimethylammonium & 1.26 & $550 \pm 57$ & $127 \pm 8$ & $125 \pm 14$ & $62 \pm 3$ & $102 \pm 3$ & $5 \pm 0.6$ & $19 \pm 2$ & $1.55 \pm 0.37$ \\
\hline 4-aminobenzylamine & 1.1 & $31 \pm 2$ & $45 \pm 9$ & $36 \pm 3$ & $21 \pm 3$ & $23 \pm 2$ & $\begin{array}{ll}1.35 & \pm \\
0.18 & \end{array}$ & $18 \pm 2$ & $0.71 \pm 0.1$ \\
\hline 4-nitrobenzylamine & 1.18 & $34 \pm 3$ & $34 \pm 3$ & $45 \pm 4$ & $23 \pm 3$ & $25 \pm 3$ & $3.49 \pm 0.6$ & $17 \pm 1.5$ & $0.9 \pm 0$ \\
\hline 4-methoxybenzylamine & 1.2 & $33 \pm 3$ & $37 \pm 5$ & $29 \pm 4$ & $20 \pm 2$ & $31 \pm 3$ & $2.1 \pm 0.3$ & $12 \pm 1$ & $0.48 \pm 0.1$ \\
\hline 4-(triflouromethyl)benzylamine & 1.26 & $66 \pm 10$ & $38 \pm 5$ & $44 \pm 5$ & $15 \pm 3$ & $27 \pm 3$ & $2.26 \pm 0.4$ & $8 \pm 1$ & $0.71 \pm 0.2$ \\
\hline 4-aminomethyl benzoic acid & 1.2 & $1 \pm 0.2$ & $2 \pm 0.4$ & $3 \pm 0.3$ & $4 \pm 1$ & $10 \pm 3$ & $2.08 \pm 0.1$ & $10 \pm 1$ & $0.4 \pm 0.02$ \\
\hline aniline & 0.84 & $0.5 \pm 0.1$ & $3 \pm 0.5$ & $3 \pm 0.5$ & $5 \pm 2$ & $12 \pm 1$ & $0.1 \pm 0.02$ & $6 \pm 1$ & $0.04 \pm 0.01$ \\
\hline
\end{tabular}


Table S6. McGowan molar volume (Vx) and sorption coefficients (L/kg) of pharmaceutical based compounds for five aluminosilicates

\begin{tabular}{|c|c|c|c|c|c|c|}
\hline Compound & $\begin{array}{l}x \\
\left(\mathrm{~cm}^{3} / \mathrm{mol}\right)\end{array}$ & $\begin{array}{l}K_{d} \quad(\mathrm{~L} / \mathrm{kg}) \\
\text { Hectorite }\end{array}$ & $\begin{array}{l}K_{d}(\mathrm{~L} / \mathrm{kg}) \quad \mathrm{Tx}- \\
\text { montmorillonite }\end{array}$ & $\begin{array}{l}K_{d}(\mathrm{~L} / \mathrm{kg}) \\
\text { Nontronite }\end{array}$ & $\begin{array}{l}K_{d}(\mathrm{~L} / \mathrm{kg}) \\
\text { Chlorite }\end{array}$ & $\begin{array}{l}K_{d}(\mathrm{~L} / \mathrm{kg}) \\
\text { Illite }\end{array}$ \\
\hline Atenolol & 2.24 & $493 \pm 39$ & $135 \pm 15$ & $117 \pm 13$ & $\overline{6 \pm 1}$ & $146 \pm 9$ \\
\hline Desipramine & 2.35 & $1004 \pm 13$ & $1629 \pm 104$ & $363 \pm 6$ & $3 \pm 0.4$ & $264 \pm 27$ \\
\hline Metoprolol & 2.32 & $310 \pm 53$ & $244 \pm 19$ & $36 \pm 8$ & $4 \pm 0.6$ & $100 \pm 17$ \\
\hline Propranolol & 2.35 & $905 \pm 42$ & $1247 \pm 108$ & $99 \pm 20$ & $5 \pm 1$ & $207 \pm 25$ \\
\hline Tramadol & 2.39 & $577 \pm 24$ & $530 \pm 47$ & $208 \pm 21$ & $5 \pm 0.9$ & $99 \pm 11$ \\
\hline Ciprofloxacin & 2.48 & $605 \pm 44$ & $821 \pm 77$ & $888 \pm 88$ & $15 \pm 2$ & $540 \pm 55$ \\
\hline Clomipramine & 2.61 & $1166 \pm 77$ & $900 \pm 45$ & $598 \pm 33$ & $28 \pm 1$ & $150 \pm 17$ \\
\hline Serotonin & 1.51 & $161 \pm 28$ & $30 \pm 2$ & $173 \pm 13$ & $14 \pm 1.5$ & $70 \pm 18$ \\
\hline Triprolidine & 2.45 & $1953 \pm 60$ & $581 \pm 44$ & $279 \pm 13$ & $15 \pm 1$ & $123 \pm 31$ \\
\hline
\end{tabular}




\section{Sorbate charge effects}

Additional insights into near-surface charge and polarity effects on organic cation sorption were obtained by examining sorption trends among sorbates with $\mathrm{pH}$-dependent charge groups. The test compounds were 4aminomethylbenzoic acid that is a zwitterion at $\mathrm{pH} 6.7$, with both positive amine $\left(\mathrm{pK}_{\mathrm{a}}=9.53\right)$ and negative carboxylate $\left(\mathrm{pK}_{\mathrm{a}}=3.87\right)$ groups, and aniline that is a neutral species (amine $\left.\mathrm{pK}_{\mathrm{a}}=4.87\right)$. The speciation of the sorbed compounds was confirmed by comparing $K_{d}$ values measured at $\mathrm{pH} 6.7$ and $\mathrm{pH} 8$ for hectorite (highest $\mathrm{CEC}$ ) and Tx-montmorillonite (lowest CEC). It is known that proton attraction to the aluminosilicate surface can cause the near-surface $\mathrm{pH}$ to be as much as 2 units lower than in the bulk solution, ${ }^{6,7}$ resulting in a shift of the near-surface sorbate speciation towards more protonated forms than assumed from the bulk solution conditions. Sorption coefficients for benzylamine, which is cationic under both solution conditions, showed no changes in $\log K_{d}$ value for either aluminosilicate between $\mathrm{pH} 6.7$ and 8, indicating that the aluminosilicate cation exchange capacities did not change with the change in solution chemistry. Sorption coefficients for 4-aminomethylbenzoic acid and aniline were about a factor of 2 lower at $\mathrm{pH} 8$ than for $\mathrm{pH} 6.7$ which was consistent with the bulk of the sorbed compound species being present as the deprotonated zwitterion (4-aminomethylbenzoic acid) or neutral (aniline) forms under both $\mathrm{pH}$ conditions. A larger reduction in $K_{C E C}$ values from $\mathrm{pH} 6.7$ to 8 would have been expected if either 4-aminomethylbenzoic acid or aniline were sorbed predominantly in the cationic form at $\mathrm{pH}$ 6.7. ${ }^{8}$ 


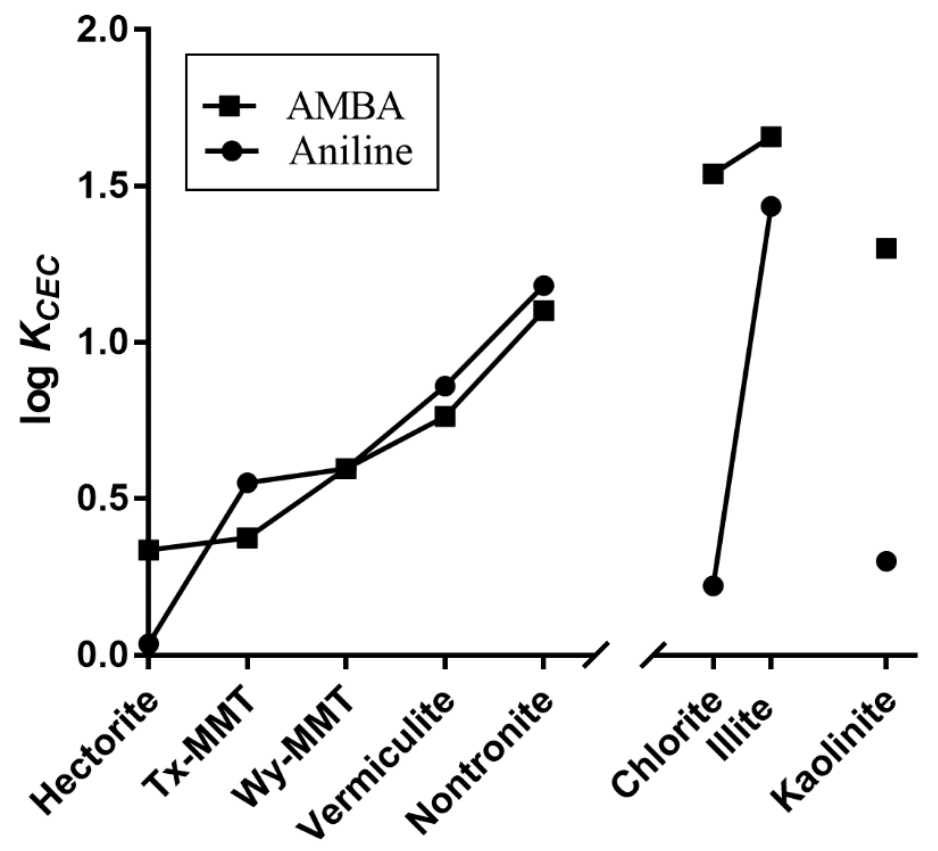

Figure S6. $\log K_{C E C}$ values at bulk solution $\mathrm{pH}$ of 6.7 for AMBA (black circles) and aniline (black squares) increase with increasing fraction of tetrahedral charge sites for aluminosilicates both with and without an interlayer. Aluminosilicates on the left of the break contain an interlayer, while aluminosilicates without an interlayer are on the right.

4-aminomethylbenzoic acid and aniline sorption to the test aluminosilicates showed trends that could be explained by electrostatic repulsion of sorbate negative charge from the negative charge density on the aluminosilicate. First, we note that $K_{C E C}$ values for 4-aminomethylbenzoic acid and aniline were 1.5 to $0.5 \log$ units lower than for benzylamine with the same aluminosilicate (Figure S5). This observation was consistent with the absence of net positive charge for both of these compounds, resulting in lowered extent of favorable interaction with the negatively-charged aluminosilicate surfaces. Similar $K_{C E C}$ values were obtained for both 4aminomethylbenzoic acid and aniline with each of the aluminosilicates, with the exception of chlorite and kaolinite. Although the localized -1 charge of the 4-aminomethylbenzoic acid carboxylate group might easily be 
expected to repel this sorbate from the aluminosilicate surface, examination of the potential energy surface maps for aniline showed the electron-donating characteristics of the aniline amine group to also result in a region of localized negative charge on the aniline ring structure and thus have a similar surface electrostatic characteristics as 4-aminomethylbenzoic acid. This similarity in electrostatic potential distributions between 4aminomethylbenzoic acid and aniline likely explained why sorption coefficients increased from hectorite, with a low positive electrostatic barrier, to nontronite, with a high electrostatic potential barrier in the interlayer (Figure S3). The positive electrostatic potential that created a barrier to nontronite sorption for cations with defocused positive charge appeared to shield the repulsion of sorbates with regions of negative electrostatic potential.

Such electrostatic interactions could also explain why chlorite and illite showed higher sorption of 4aminomethylbenzoic acid than montmorillonite and vermiculite. The external location of charge sites for chlorite and illite could allow sorbates to orient perpendicular to the surface, thereby maximizing the distance between the aluminosilicate surface and the regions of negative charge density on the sorbate molecule. ${ }^{4}$ It is not clear why 4-aminomethylbenzoic acid and aniline $K_{C E C}$ values diverged for chlorite and illite, whereas values were quite similar for the two compounds with the interlayer structural analogue aluminosilicates, montmorillonite and vermiculite. Overall, the trend of higher $K_{C E C}$ values for 4-aminomethylbenzoic acid and aniline with aluminosilicates without interlayers, compared to aluminosilicates with interlayers, suggests more favorable sorption to chlorite and illite than the corresponding aluminosilicates with interlayers present. 


\section{References}

1. Ponder, J. W.; Richards, F. M., An efficient newton-like method for molecular mechanics energy minimization of large molecules. Journal of Computational Chemistry 1987, 8 (7), 1016-1024.

2. Samaraweera, M.; Jolin, W.; Vasudevan, D.; MacKay, A. A.; Gascón, J. A., Atomistic prediction of sorption free energies of cationic aromatic amines on montmorillonite: a linear interaction energy method. Environmental Science \& Technology Letters 2014, 1 (6), 284-289.

3. Schenzel, J.; Goss, K.-U.; Schwarzenbach, R. P.; Bucheli, T. D.; Droge, S. T., Experimentally determined soil organic matter-water sorption coefficients for different classes of natural toxins and comparison with estimated numbers. Environmental science \& technology 2012, 46 (11), 6118-6126.

4. Vasudevan, D.; Arey, T. A.; Dickstein, D. R.; Newman, M. H.; Zhang, T. Y.; Kinnear, H. M.; Bader, M. M., Nonlinearity of cationic aromatic amine sorption to aluminosilicates and soils: Role of intermolecular cation- $\pi$ interactions. Environmental science \& technology 2013, 47 (24), 14119-14127.

5. Jolin, W. C.; Sullivan, J.; Vasudevan, D.; MacKay, A. A., Column chromatography to obtain organic cation sorption isotherms. Environmental science \& technology 2016, 50 (15), 8196-8204.

6. Jones, A. D.; Bruland, G. L.; Agrawal, S. G.; Vasudevan, D., Factors influencing the sorption of oxytetracycline to soils. Environmental toxicology and chemistry 2005, 24 (4), 761-770.

7. Vasudevan, D.; Bruland, G. L.; Torrance, B. S.; Upchurch, V. G.; MacKay, A. A., pH-dependent ciprofloxacin sorption to soils: Interaction mechanisms and soil factors influencing sorption. Geoderma 2009, $151(3-4), 68-76$.

8. Carrasquillo, A. J.; Bruland, G. L.; MacKay, A. A.; Vasudevan, D., Sorption of ciprofloxacin and oxytetracycline zwitterions to soils and soil minerals: influence of compound structure. Environmental science \& technology 2008, 42 (20), 7634-7642. 